\title{
ISOLASI ACTINOMYCETES DARI TANAH KEBUN SEBAGAI BAHAN PETUNJUK PRAKTIKUM MIKROBIOLOGI
}

\author{
Pujiati \\ Program Studi Pendidikan Biologi, FPMIPA IKIP PGRI MADIUN \\ E-mail: poesky86@gmail.com
}

Diterima 21 Agustus 2014 di setujui 26 Oktober 2014

\begin{abstract}
The objective of this study was to isolate actinomycetes from soil of tea plantations, Jamus ngawi as a microbiology lab manual chapter isolation and characterization of microbes. The medium used is the medium of MHA and MHB. Soil samples taken to a depth of 10-15 cm from the surface with capture location is about $07^{\circ} 41^{\prime} 53,07$ 'S and $111^{\circ} 37^{\prime} 24.64$ " E. The isolates were obtained observed morphologic characters include colony shape, colony color, surface characteristics of colonies, colony growth, colony elevation, and the edge of the colony. Isolates of actinomycetes were successfully isolated are Streptomyces, Nocardia and Nocardiopsis. Actinomycetes isolates have been found that can be used as a collection of the microbiology laboratory.
\end{abstract}

Keywords : actinomycetes, soil of tea plantation, microbiology lab manual

\section{PENDAHULUAN}

Tanah merupakan salah satu habitat bagi mikroorganisme, dalam satu gram tanah terdapat jutaan mikroorganisme. Populasi mikroorganisme per gram tanah yang subur meliputi : bakteri (2.500.000.000), actinomycetes (700.000), fungi (400.000), algae (50.000) dan protozoa (30.000) (Budiyanto,2004). Sebagai mana makhluk hidup lainnya, terdapat hubungan antara mikroorganisme satu dengan lainnya yang hidup berdekatan dalam satu habitat. Hubungan ini dapat berupa netralisme, mutualisme, komensialisme, parasitisme, kompetisi, atau antagonisme. Hubungan antagonisme inilah yang sebenarnya menguntungkan bagi kehidupan manusia, karena dengan adanya antagonisme dimungkinkan suatu jenis mikroorganisme menghasilkan zat anti mikrobial yang dapat menghambat kehidupan mikroorganisme jenis lain.

Zat anti mikrobial yang dihasilkan oleh mikroorganisme tertentu bisa saja berperan sebagai anti bakteri atau anti fungi. Apabila suatu mikroorganisme terbukti menghasilkan zat anti mikrobial maka mikrorganisme tersebut berpotensi sebagai penghasil antibiotik. Saat ini banyak penelitian yang difokuskan pada actinomycetes yang diindikasikan sebagai bakteri yang mampu menghasilkan antibiotik terbanyak. Sekitar 70\% dari antibiotik yang telah ditemukan dihasilkan oleh actinomycetes terutama streptomyces (Suwandi, 1993). Menurut Okami (1988), hampir 95\% dari 2000 antibiotik yang ada dihasilkan oleh streptomyces. Actinomycetes termasuk bakteri yang berbentuk batang, gram pasitif, bersifat anaeraob atau facultatif. Struktur actinomycetes berupa filament lembut yang sering disebut hyfa atau mycelia, sebagai mana yang terdapat pada fungi, memiliki konidia pada hyfa yang menegak.

Actinomycetes merupakan bakteri yang bereprodusi dengan pembelahan sel, rentan terhadap penisilin, tetapi tahan terhadap zat antifungi (Rollin, 2000). Beberapa antibiotik yang dihasilkan oleh streptomyces, yaitu aureomycin yang dihasilkan oleh S.aureofaciens, oleandomycin (oleh S. Antibioticus), dan spiramycin (oleh S. Ambofaciens) (Dwidjoseputro, 1989).

Habitat actinomycetes, terutama streptomyces adalah ditanah, bahkan 70\% mikroorganisme yang ada ditanah adalah streptomyces (Rao, 2001). Keberadaan actinomycetes dalam tanah telah banyak 
dikaji peneliti. Sebanyak 22 genus actinomycetes telah berhasil diisolasi dari sampel tanah yang berasal dari 12 tempat di Yunnan dan 91\% diindikasikan sebagai streptomyces (Jiang, 1990). Sementara itu Runmao, et al. (1994) juga berhasil menemukan 4520 actinomycetes pada sampel tanah yang berasal dari 34 lokasi ladang pertanian dan non pertanian di Cina bagian timur laut. Di Sabah juga telah ditemukan sebanyak 78 strain actinomycetes yang diisolasi dari tanah yang berasal dari 22 lokasi ( Lo, et al., 2002).

Oskay, et al. (2004), berhasil menemukan 50 strain actinomycetes yang berbeda padaa sampel ladang pertanian yang diambil dari daerah Manisa di Turki. Ternyata 34\% dari keseluruhan isolat berpotensi sebagai penghasil anti biotik, dan 7 isolat menghasilkan antibiotik baru. Penelitian Nedialkova (2005), juga berhasil menemukan 40 strain actinomycetes yang di isolasi dari antartika. Setelah diujikan pada 7 spesies bakteri didapatkan hasil $60 \%$ strain berpotensi sebagai penghasil antibiotik, dan 10 strain mempunyai daya hambat dengan spektrum yang luas.

Tanah pekarangan dan perkebunan juga merupakan habitat bagi actinomycetes. MenurutJiang (1990), pada tanah yang lebih kering, lebih tandus dan lebih dingin, lebih banyak ditemukan streptomyces. Tanah perkebunan teh di Jamus, tanahnya cukup kering dan cukup dingin. Dengan kondisi seperti diatas dimungkinkan perkebunan ini akan ditemukan actinomycetes khususnya streptomyces. Tujuan dari penelitian ini adalah untuk mengetahui jumlah dan jenis isolat actinomycetes yang dapat ditemukan di tanah perkebunan teh Jamus, Ngawi. Isolat-isolat actynomycetes tersebut akan digunakan sebagai bahan dalam pengamatan mikroba.

Praktikum mikrobiologi bab pengamatan karakter mikroba dilakukan dengan mengkarakterisasi mikroba baik itu fungi, yeast, bakteri dan actinomycetes.

\section{METODE}

Pengambilan sampel dalam penelitian ini adalah di tanah rizosfer perkebunan teh Jamus, Ngawi, sedang tempat pemeriksaan di labolatorium biologi Fakultas Pendidikan Matematika dan Ilmu Pengetahuan Alam IKIP PGRI Madiun.

Penelitian ini dilaksanakan selama 6 bulan. Bahan-bahan yang digunakan adalah tanah perkebunan jamus, akuades, alkohol $70 \%$ kapas, kasa steril, kertas cakram berdiameter $6 \mathrm{~mm}$ (Oxoid), medium SCN (Plate Count Agar), medium PDA (Potato Dextrose Agar), medium PDY (Potato Dextrose Broth + Extract Yeast), medium MHA (Muller Hinton Agar), medium MHB (Muller Hinton Broth) dan natrium hipoklorit $1 \%$.

Alat-alat gelas yang lazim digunakan di laboratorium mikrobiologi (tabung rekasi, cawan petri, gelas Beaker, labu Erlenmeyer, gelas ukur), neraca analitik (Shimadzu AEL-200), pH meter, autoklaf (Ogawa Seiki), vortex, $\mathrm{pH}$ meter, soil tester, higrometer, shaker inkubator, spektrofotometer jarum ose bulat, jarum ose lurus, lampu spiritus, lemari pendingin (Panasonic), mikropipet, pinset, tabung sentrifuse, tabung reaksi, timbang-an analitik (Chyo), tip.

Populasi dalam penelitian ini adalah seluruh tanah di tanah rizosfer perkebunan teh Jamus, Ngawi. Sedangkan sampel diambil dari 5 lokasi di perkebunan tersebut. Pada lokasi yang dipilih diambil tanahnya pada kedalaman 10-15 cm dari permukaan tanah. Tanah sampel dari 5 lokasi tersebut dicampur dan dibawa ke laboratorium. Koleksi sampel tanah dilakukan dengan : sampel tanah diambil secara aseptis.

Penentuan $\mathrm{pH}$ sampel tanah dilakukan dengan : diambil kira-kira 2 gram sampel tanah lalu dimasukkan dalam beacker glass ukuran $50 \mathrm{ml}$ dan ditambahkan aquadest sedikit demi sedikit sambil di aduk dengan batang gelas. Penambahan lalu dibiarkan selama 30 menit sampai 1 jam. Pengukuran nilai $\mathrm{pH}$ dilakukan dengan $\mathrm{pH}$ meter kemudian dibaca dan di catat. Pengukuran dilakukan selama tiga kali dan hasilnya dirata-rata.

Masing-masing $10 \mathrm{~g}$ sampel yang telah ditimbang dimasukkan pada botol kultur yang telah berisi $90 \mathrm{~mL}$ akuades yang 
telah disterilkan sebelumnya, kemudian Divortex selanjutnya dishaker selama 15 menit dengan kecepatan $100 \mathrm{rpm}$, setelah itu didiamkan selama +15 menit untuk kemudian diambil suspensinya $+1 \mathrm{~mL}$ ke dalam cawan petri. Suspensi ditambahkan dengan kloramfenikol sebanyak $+1 \mathrm{~mL}$ dan ditambahkan media SCN (Starch Casein Nitrat) agar ke dalam cawan petri menggunakan metode tuang. Setelah itu diinkubasi pada suhu $37^{\circ} \mathrm{C}$ selama $7-14$ hari.

Identifikasi morfologi makroskopis meliputi: bentuk koloni,warna koloni, karakteristik permukaan koloni, pertumbuhan koloni, elevasi koloni, dan tepi koloni. Sedangkan untuk identifikasi morfologi mikroskopis dilakukan pewarnaan untuk menentukan bentuk sel dan gram apakah isolat tersebut serta menggunakan slide kultur untuk melihat konidia dan hifanya. isolat yang telah di purifikasi di inokulasi pada media Oatmeal Agar. Langkahnya dengan mengambil satu ose isolat dan ditumbuhkan secata streak pada media Oatmeal Agar. Medium yang telah diinokulasi diinkubasi pada suhu $28^{\circ} \mathrm{C}$ selama 2 minggu. Diamati warna isolat yang tumbuh.

\section{HASIL}

Adapun data yang berhasil dikumpulkan dalam peneltian ini adalah:

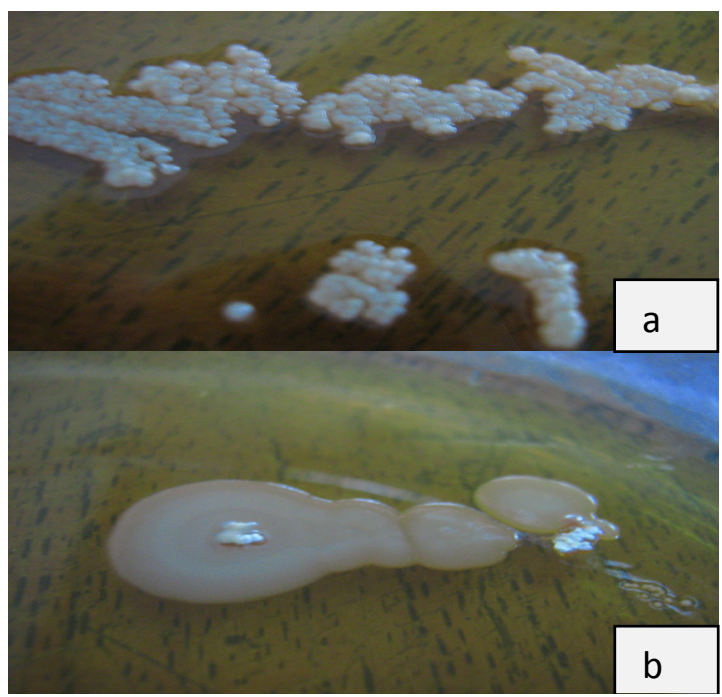

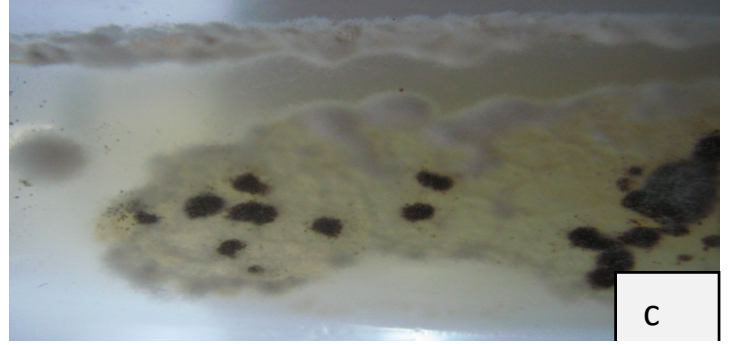

Gambar 1. Actinomycetes yang berhasil diisolasi dari tanah pekarangan, a) Nocardia, b) Streptomyces, c) Nocardiopsis

\section{PEMBAHASAN}

Penelitian ini bertujuan untuk mengisolasi Actinomycetes dari sampel tanah yang diambil di perkebunan teh Jamus, Ngawi. Untuk isolasi pada cawan petri ditambahkan $1 \mathrm{ml}$ griseofulvin untuk mematikan kapang agar tidak ikut tumbuh serta $1 \mathrm{ml}$ kloramfenikol untuk mematikan bakteri. Actinomycetes merupakan mikroba yang hanya tumbuh pada tanah subur sehingga dapat juga digunakan sebagai indikator kesuburan suatu lahan .

Pada penelitian ini dilakukan karakterisasi koloni dari beberapa isolat actinomycetes yang berhasil diisolasi Ciri-ciri dari isolat yang didapat adalah morfologi selnya sangat beragam dan pleimorfik, bentuk batang tak beraturan, filamen bercabang merupakan struktur miseliumnya; non motil; Gram positif; Aerobik, anaerobik fakultatif atau anaerobik dan habitat.

Karakter koloni dari ketiga genus hampir mirip jika telah bersporulasi dan biasanya dapat dibedakan antara warna koloni bagian atas dan bawah, untuk lebih memastikan dilakukan pengamatan mikroskopis. Biasanya bila koloni sudah tua akan terjadi kerutan-kerutan atau juga bentukan seperti serbuk bila ditanam pada media agar yang merupakan spora dari mikroba ini. Nocardia memiliki tekstur seperti beludru bila bersporulasi yang merupakan miseliumnya, warna koloni bagian bawah berwarna merah sedangkan tekstur koloni yang belum bersporulasi mengkerut-kerut dibagian tengah koloni, unisel, reversenya tidak berwarna. Streptomyces yang belum bersporulasi 
bentuk koloni mirip bakteri yaitu konveks, tepi rata, warna krem, permukaan berfilamen, reverse tidak bewarna dan reverse berwarna merah untuk yang sudah bersporulasi. Nocardiopsis memiliki tekstur koloni seperti beludru, yang merupakan miseliumnya dan atas koloni berwarna putih dan bawah berwarna krem. Streptomyces merupakan salah satu genus dari actinomycetes yang bermanfaat karena menghasilkan antibiotik jenis streptomycin yang sangat berguna dibidang kesehatan.

\section{SIMPULAN}

1. Actinomycetes merupakan transisi antara kapang dan bakteri karena bentuknya, sehingga disebut sebagai bakteri berhifa.

2. Nocardia memiliki tekstur seperti beludru bila bersporulasi yang merupakan miseliumnya, warna koloni bagian bawah berwarna merah sedangkan tekstur koloni yang belum bersporulasi mengkerutkerut dibagian tengah koloni, unisel, reversenya tidak berwarna.

3. Streptomyces yang belum bersporulasi bentuk koloni mirip bakteri yaitu konveks, tepi rata, warna krem, permukaan berfilamen, reverse tidak bewarna dan reverse berwarna merah untuk yang sudah bersporulasi.

4. Nocardiopsis memiliki tekstur koloni seperti beludru, yang merupakan miseliumnya dan atas koloni berwarna putih dan bawah berwarna krem.

\section{DAFTAR PUSTAKA}

Ambarwati dan Trisnawati,A. G, 2008. Isolasi Actinomycetes dari Tanah Sawah sebagai Penghasil Antibiotik. Laporan Penelitian Dosen Muda Dikti. Antanova-Nikolova, S., Tzekova, N. (a) Yocheva, L.,2005, Taxonomy of Streptomyces sp. Strain 3B, Journal of Collection, vol. 4 pp: 36-42.

Budiyanto, M.A.K., 2004, Mikrobiologi

Terapan, UMM press, Malang.

Crueger, W and A. Crueger. 1994.
BIOTECHNOLOGY: A Textboook of Industrial Microbiology. Science Tech, Inc. USA. P.12-13, 54-59.

Dwidjoseputra, D. 1989. Dasar-Dasar Mikrobiologi. Penerbit Djambatan, Malang. Industrial Microbiology. Science Tech, Inc. USA. P.12-13, 5459.

Ganiswara, S.G. 1995. Farmakologi dan Terapi. Edisi 4. Fakultas Kedokteran Universitas Indonesia. Jakarta. Hal.571-572.

Jawetz, Melnick and Adelberg's. 1991. Medical Microbiology, Twentieth Edition. Prentice Hall International Inc. USA. P.80.

Jiang, C-L, \& Xu, L-H, 11990, Characteristics Of The Populations Of Soil Actinomycetes In Yunani, journal : Actinomycetes, 1990 Vol. 1, part.3.pp : 67-74. ISSN : 0732-0574, Depkes .

Korn-Wendisch, F., \& kutzner, H. J. 1992. The family Streptomycetaceae. In The Prokaryotes, A Hanbook on The Biology of Bacteria : Ecophysiology, Isolation, Identification, Aplications. Second Edition. ( A. Balows, H. G. Truper, M. Drowkin, W. Harder, \& karlHeinz Schleifer. Eds). Springer-Verlag, New york, berlin, Heidelberg, London, Paris, tokyo, Hongkong, barcelona, \& Budapest.

Lee, J. Y., \& Hwang, B.K., 2002. Diversity of AntifungalnActinomycetes in varios Vegetativ Soils of Korea. Diakses : senin, 17 april 2014. http:// www.ncbi.nlm.nih.gov/entrez/query. fegi? $\mathrm{CMD}=$ search $\& \mathrm{DB}=$ pubmed

Lo, C. W., Lai, N. S., Cheah, H-Y., Wong, N. K. I@ HO, C. C, 2002, Actinomycetes Isolated From Soil Samples From The Crocker Range Sabah ASEAN. review of Biodiversity and Environmental Conservation (ARBEC), Juli-september 2002.

Madingan, M. T., Martinko, J. M., \& Parker, J. 2003. Brock Biology of Microorganisms. Tent Edition. Prentice Hall, USA.

Mutschlear, E. 1991. Dinamika Obat, Buku Ajar Farmakologi dan Toksikologi. Edisi Kelima. Ahli Bahasa Widianto, 
M. B. \& Ranti, A.S penerbit ITB, Bandung.

Nedialkova, D. \& Naidenova, M. 2005. Screening the Antimicrobial Acctivity of Actinomycetes Strains Isolated from Antartica. Journal of Culture Collections, Vol. 4,pp : 29-35.

Okami, Y., \& Hotta, K., 1988. Search and Discovery of New Antibiotics. In, Actinomycetes in Biotechology. Goodfellow, M., Williams, S., T and Mordaski, M., (ED).

Oskay, M., Tamer, A. U. \& Azeri, C., 2004, Antibacterial Activity of some Actinomycetes Isolated from farming Soil of Turkey, African journal of Biotechnology Vol.3 (9) : pp. 441-446, september 2004, ISSN 1684-5315.

Panagan, A.T, 2011, Isolasi Mikroba Penghasil Antibiotika dari Tanah Kampus Unsri Indralaya Menggunakan Media Ekstrak Tanah.Jurnal Penelitian Sains. Vol.14, no 3 (C).

pelczar, M. J. \& Chn, E. C. S., 1988, DasarDasar Mikrobiologi, Alih Bahasa Hadioetomo, R. S., Imas, Tjitrosomo, S. S., dan Angka, S. L., UI Press, Jakarta.

Prescott, L. M., Harley, J. P.,\& Klein, D. A. 1999. Microbiology. Fourth Edition. WCB McGraw-Hill, Boston.

Rao, N.,S.,S.,2001, soil Microbiology, Foutrh editions of Soil Microorganisme and Pland Growth. Science Publishers, Inc. Enfield (NH), USA.

Rollins, D. M. \& Joseph, S. W.,2000, Actinomycetes Summary, University of Maryland.

Runmao, H.,Lianjun, M. \& Guizhe, W.,1994, Distribution of soil Actinomycetes in Nort-East china, journal Actinomycetes, vol. 5, part 1, 12-13,1994.ISSN:0732-0574 